NASA Technical Memorandum 86724

A Numerical Simulation of the NFAC (National Full-Scale Aerodynamics Complex) OpenReturn Wind Tunnel Inlet Flow

Upender K. Kaul, James C. Ross, and James L. Jacocks

April 1985

LIRUMEY ERPY

$$
\text { 1. . } 1=35
$$

LANGLEY FESEARCH CENTER LIORARY, NASA

MUTONO VIRGINIA

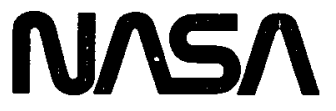

Natıonal Aeronautics and Space Admınıstratıon 


\section{A Numerical Simulation of the NFAC (National Full-Scale Aerodynamics Complex) Open- Return Wind Tunnel Inlet Flow}

Upender K. Kaul, Informatıcs General Corp., Palo Alto, Calıfornia James C. Ross, Ames Research Center, Moffett Field, Calıfornıa and

James L. Jacocks, Calspan, AEDC, Tullahoma, Tennessee

April 1985

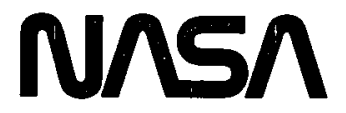

Natıonal Aeronautics and

Space Adminıstratıon 


\title{
A NUMERICAL SIMULATION OF THE NFAC (NATIONAL FULL-SCALE AERODYNAMICS COMPLEX) OPEN-RETURN WIND TUNNEL INLE'T FLOW
}

\author{
Upender K. Kaul ${ }^{*}$, James C. Ross $†$ \\ NASA Ames Research Center, MoIfett Field, Calıfornıa \\ and \\ James L Jacocks $\dagger$ \\ Calspan, $\Lambda E D C$, Tullahoma, Tennessee
}

\begin{abstract}
$\underline{\text { Abstract }}$
The flow into an open return wind tunnel inlet was simulated using Euler equations $\mathrm{An}$ explicıt predictor-corrector method was employed to solve the system. The calculation is timeaccurate and was performed to achieve a steadystate solution. The predictions are in reasonable agreement with the experimental data Wall pressures are accurately predicled except in a region of recirculating flow. I'low-licld surveys agree qualitatıvely with laser velocimeter measurements The method can be used in the design process for open-return wind tunnels
\end{abstract}

\section{Introduction}

The design of low-epeed wind tunuels has received a great deal of attention recently because of the need for improved and larger wind tunnels to advance the technology of low-speed fight In the past, the design process has been more of an experimental procedure, which requires extensive model and prototype testing Computational fluid dyamics, however, is now sufficiently advanced so it can be used to assist such a design process and thercby reduce the amount of testing required The purpose of the present investigation is to numerically analyze the acrody namics of the inlet of the $80 \times 120$ open return wind tunnel of the National Pull-Scale Aerodynamies Comples (NFAC) as part of an effort to improve the testsection flow quality.

Since the acrodynamics of wind tunnels is complex, it is clivided into a study of the components; for example, into the individual studies of inlet, contraction nozzle, diliuser, etc. The inlet flow

\footnotetext{
*Principal Analyst, Informatics General Corporation, Palo AIto, CA; Member AIAA

$\dagger$ Aerospace Enginecr, Member AIAA

tt Supervisor, Propulsion Wind Tunnel Facility, $\Lambda$ EDC Division; Member AIAA
}

This paper is declared a work of the U S Government and therefore is in the public domain here constitutes the flow in the inlet section, contraction nozzle, and test-section of a flow-llirough facility. The purpose of the inlet is to tahe atr from the atmosphere, condition it for the wind tunnel circuit, and accelerate it through the bellmouth to the test-section with minimal turbulence and minimal large scale disturbances The inlet now is therefore strongly dependent on the nature of the atmospheric winds and turbulence, and on the inlel geometry The downstrean efrect of the fan and diffuser section on the inlet llow will usually be negligible The test-section llow quality is evaluated in terms of the flow steadıness, uniformity, angularity, turbulence level, boundary layer growtl, etc. The present numerical study was undertaken to examine the ability of an Fuler method to accurately predich some of these features in the flow field of the inlet part of the circuit

\section{Problem Definition}

The inlet flow is simulated using the unstendy compressible Euler equations in three dimensions. The solution is obtamed by marching in time to a steady state. The equations are solved usıng MacCormack's explicit predictor-corrector scheme ${ }^{1}$ in Cartesian coordinates with a finte volume formulation. The Euler code ${ }^{2}$ is modhlied to admit a zonal calculation wilhout having to read in from or out to a disk This is macle possible by definung a single inders for all the grid points in the computational domain, thereby reducing the storage requirement The computations were carred out on the Cray-Xillp computer al NASA Ames Research Ceuter The code was used to sumulate the flow induced in the wind tunnel by a fan downstrean of the test section (sink-type flow). The predictions are compared with" the experimental data, the pressures and the velocities are compared at different locations, and the velocity vectors are plotted to compare the predicted flow pattern with that obtained by laser velocimeter measure' ments. 


\section{Formulation}

The three-dimensional, unsteady Euler equations in conservation form and in cartesian coordinates are given by.

$$
\partial_{t} Q+\partial_{x} E+\partial_{y} G+\partial_{z} H=0,
$$

$$
\begin{aligned}
\text { where } Q & =\left[\begin{array}{l}
\rho \\
\rho u \\
\rho v \\
\rho w \\
e
\end{array}\right], \quad E=\left[\begin{array}{l}
\rho u \\
\rho u^{2}+p \\
\rho u v \\
\rho u w \\
(e+p) u
\end{array}\right], \\
G & =\left[\begin{array}{l}
\rho v \\
\rho u v \\
\rho v^{2}+p \\
\rho v w \\
(e+p) v
\end{array}\right], \text { and } H=\left[\begin{array}{l}
\rho w \\
\rho u w \\
\rho v w \\
\rho w^{2}+p \\
(e+p) w
\end{array}\right]
\end{aligned}
$$

$\mathrm{Q}$ is the solution vector, $\mathrm{E}, \mathrm{G}$ and $\mathrm{H}$ are the fluxes In the $x, y$ and $z$ directions respectively, and the pressure is given by

$$
\begin{aligned}
& \quad p=(\gamma-1)\left(e-\frac{1}{2} \rho q^{2}\right), \\
& \text { where } q^{2}=u^{2}+v^{2}+w^{2}
\end{aligned}
$$

The physical variables above are normalized with respect to the free-stream density and free-stream speed of sound c Writing equation (1) as

$$
\partial_{t} Q+\nabla \quad F=0
$$

where $F=(E, G, H)$, the Euler equations can be expressed in integral form by integrating them over a small stationary volume element $V$ as

$$
\int_{V} \partial_{t} Q+\int_{V} \nabla \cdot F=0
$$

Using the mean value and divergence theorems, the integral form reduces to

$$
\partial_{t} Q=-\frac{1}{V} \int_{S} \vec{n} \cdot F d S
$$

where $Q$ is redefined to be the mean value over the volume element $V$ and is evaluated at some point interior to $V$ (assumed to be its centroid for all practical purposes), $\vec{n}$ is the unit vector normal to the area element $d S$ and $S$ is the surface bounding the volume $V$.

\section{Predictor-Corrector Scheme}

The finte-volume, explicit-integration scheme used in the present study is described in Ref. 2. The basic numerical algorithm is due to MacCormack. ${ }^{1}$ The flux integral in equation (3) is approximated by summing the dot products of the area vectors and the appropriate flux vectors over each of the three orthogonal projections of the volume element $V$ Integration in time is done using a two-step predictor-corrector sequence Although the formulation is time-accurate, only steady-state solutions are sought The predictor advances the solution to time level $n+1$ as

$$
\begin{aligned}
Q_{p}^{n+1}= & Q^{n}-\frac{\Delta t}{V}\left(\sum_{1} F S_{1}^{+}\right. \\
& \left.+\sum_{i} F^{-} S_{i}^{-}\right)
\end{aligned}
$$

and the corrector updates this solution as

$$
\begin{aligned}
Q^{n+1}= & Q_{p}^{n+1}-\frac{\Delta t}{2 V}\left[\left(\sum F_{p}^{+} \cdot S_{1}^{+}+\sum_{i} F_{p} S_{i}^{-}\right)\right. \\
& \left.-\left(\sum F \cdot S_{1}^{+}+\sum_{i} F^{-} \cdot S_{1}^{-}\right)\right]
\end{aligned}
$$

where $F$ is the flux vector evaluated at the "centroid" of the volume element $V$ and $F^{+}$is the flux vector evaluated at the centroid of the volume element next to $V$ in the increasing coordinate direction given by 2 . Similarly, $F^{-}$corresponds to the volume element next to $V$ in the decreasing coordinate direction; $S$ is the area vector of any side of the hexahedral volume element in question The subscript $p$ refers to the values at the predicted level. The time step criterion for $\Delta t$ is given by the Courant-Friedrich-Lewy stability condition. The maximum allowable time step is given by

$$
\Delta t=\frac{V}{|\bar{q} \cdot S|+c|S|}
$$

where $\underline{q}$ is the velocity vector

\section{Grid Generation}

The three-dimensional grid for the inlet, Fig 1 , is generated algebraically The grid (shown in Fig 2) represents the ground plane, and the top 
and side computational boundaries upstream of the inlet, the symmetry plane midway between the side walls of the tunnel, the inlet cowls in the horizontal and the rertical directions, the nozzle and the testsection. The nozzle has a 51 contraction ratio Two planar grids are also shown in Figs 3 and 4. The z-plane represents a horizontal cut, and the $y$-plane represents a vertical cut, $F_{\text {Ig }} 3(b)$ and Fig 4(b) show enlarged views near the cowl The gnd is stretched so as to resolve the flow gradients in more detail The three-dimensional grid is generated plane by plane using an interpolation scheme.

\section{Intial Conditıons}

The computations of the inlet sink-type flow are carried out corresponding to quiescent conditions at the upstream boundary Intially, stagnation conditions exist everywhere. The pressure drop which generates the flow in the inlet and yields a given test-section velocity is introduced at the downstream boundary gradually in time The flow can be imagined to exit at the downstream boundary into ambient conditions at somewhat lower than the upstream stagnation pressure and is given by $p_{c}=p_{s}-\frac{1}{2} \rho q_{e}{ }^{2}$ in the steady incompressible limit, where the subscripts $e$ and $s$ refer to the exit and stagnation conditions

\section{Boundary Conditions}

The boundary conditions at the wall are implemented using a dummy volume concept The condition of surface tangency at solid and symmetry boundaries is enforced using the vector equation

$$
(\rho \vec{q})_{0}=(\rho \vec{q})_{s}-2 \frac{S(\rho \vec{q})_{s}}{S \cdot S} S
$$

where the subscripts $o$ and $z$ refer to the outer (dummy) and inner volume elements at the boundary, $\vec{q}$ is the velocity vector and $S$ is the area vector at this boundary across which the density, pressure and energy are reflected ${ }^{2}$ This condition reflects the mass flux vector across the boundary.

The implementation of the solid boundary condition at the convex corners (e g., B and C in Figs 3 and 4 respectively) is done in such a way that the same image (dummy) volume element is used to satisfy the boundary conditions (corresponding to surface tangency) at the two interior nodes adjacent to the corner This is done sequentially in the three coordinate directions as the fluxes are accumulated in the integration process, thereby removing the corner discontinuity. The integration process is similar to that used in Ref 3 , except that here all the fluxes are accumulated prior to updating Around such regions as the external cowl, where the curvature is relatively large, a simple reflection boundary condstion on pressure 2 is no longer valid. Therefore, the pressure at the image node next to the wall is found from the conservation of momentum normal to the cowl surface, which reduces to a balance between the centrifugal force and the pressure gradient in that direction. ${ }^{4}$ This condition is given by

$$
\partial_{n} p=\frac{\rho V^{2}}{r}
$$

which is written in difference form as

$$
p_{0}=p_{i}+\Delta n \frac{\rho V^{2}}{r}
$$

for concave surfaces and as

$$
p_{0}=p_{\imath}-\Delta n \frac{\rho V^{2}}{r}
$$

for convex surfaces, where $\mathrm{n}$ is the direction normal to the surface, $\Delta n$ is the distance between interior and dummy volume element centrolds in the normal direction, $V$ is the tangential velocity at the curved surface, and $r$ is the radius of curvature of the surface. For the downstream boundary, a nonreflecting boundary condition for the pressure ${ }^{5}$ was used while the other four independent variables were simply extrapolated The boundary condition on pressure is given by

$$
\theta_{t} p-p c \theta_{t} u+\alpha\left(p-p_{e}\right)=0
$$

where $\alpha$ is a parameter which determines the rate at which the transients die out before steady state is attained. ${ }^{5}$

The split-flux characteristic boundary conditions ${ }^{6}$ were used at the inflow boundary. Stagnation pressure, stagnation enthalpy, and the flow direction are prescribed Pressure is related to velocity along characteristics with a locally isentropic flow assumption. The inflow boundary is placed sufficiently far upstream so that the velocity gradients are small there This permits a stretched grid at the inflow boundary. 


\section{Results and Discussion}

Computations were carried out at the test section Mach number, $M=015$ The results from the computations are shown in Figs 511 The converged results correspond to a relative convergence criterion on pressure such that

$$
\left|\frac{\left(p^{m+1}-p^{m}\right)}{p^{m}}\right|<00001
$$

over the entire flow field, where $m$ is the timestep index. The velocity vector plots in the $x-y$ and $x-z$ planes as shown in Fig 5 and Fig. 6 indicate the correct qualitative behavior of the flow The separation bubble (shown in Fig. 5(c)) immediately downstream of the cowl, as observed experimentally, is not predicted in the computations since the effects of viscosity are not simulated Figure 7 shows a variation of the axial velocity normalized by the test-section velocity with the spanwise coordinate, $y$, at an $x$ station situated $27 \mathrm{ft}$ upstream of the inlet and close to the $z=0$ plane The agreement with the experiments in this case is quite good Figure 8 shows a variation of the normalized axial velocity with the vertical coordinate $z$ at $x=$ $-27 \mathrm{ft}$, near the symmetry plane between the two side walls of the tunnel. The predictions are again in good agreement with the experımental data.

Tunnel floor pressure distribution and resultant velocity along the center line given by $C_{p}\left(C_{p}\right.$ is defined with respect to the velocity and pressure at the test section) and V (at the test section), respectively, are plotted versus the downstream distance, $x$, from the cowl to the test section in Fig 9. The agreement between the present calculations and the calculations made using a panel method is good except in the region of recirculating flow immediately downstream of the cowl. Pressure variation with the downstream distance $\left(C_{p}\right.$ distribution) on the side wall centerline near the $z=0$ plane is shown in Fig 10 The comparison between the predictions and the experıment is good except near the separation bubble where the pressures are overpredicted relative to the experiment. Figure 11 shows the crossflow plane grid at three streamwise stations, $x=36,130$ and $260 \mathrm{ft}$ respectively Velocity vector plots at the corresponding streamwise stations in Fig 12 show the flow tending toward the center of the crossflow plane Figure 12 also shows that the crossflow accelerates in passing through the nozzle and then slowly decelerates as it enters the test section The tendency of the flow to be directed toward the center of the plane has also been observed in flowvisualization studies. The crossflow plane passing through the inlet cowl shows the flow following the contours of the cowl as expected A comparison between the crossflow plane velocity vectors at $x=$ $-27 \mathrm{ft}$ from laser velocimeter measurements and the computations is shown in Fig 13 The predictions are in qualitative agreement with the exper1ment

\section{Conclusions}

A three-dimensional, unsteady, inviscid flow code has been used to predict the pressures and the velocity profles inside the inlet of the NFAC. The predictions are in reasonable agreement with the experiment. Although the viscous effects are not accounted for, many features of the inlet flow are captured satisfactorily The general flow direction is predicted in accord with laser-doppler annemometer studies The pressure variation on the solid walls as well as the flow velocities are close to the experimental values However, viscous effects such as separated flow regions, secondary flows, and turbulence can be simulated only through a viscous flow computation However, using the present approach, various design criteria such as pressure losses and the desired test section flow uniformity can be estimated, given the geometry and the fan characteristics of an openreturn circuit The results of the computations indicate that the Euler calculations can be used to simulate the flow in open-return wind tunnel inlets

\section{Acknowledgements}

The assistance of $\mathrm{Mr} \mathrm{T}$. L Donegan of Calspan, AEDC in providing the original iersion of the flow code is appreciated The experimental data was graciously provided by $\mathrm{Dr} J \mathrm{~J}$ van Ahen of the University of Kausas Center for Research, Inc and Mr M S Reinath of NASA Ames Research Center

\section{$\underline{\text { References }}$}

1 MacCormack, $\mathrm{R} W$, "The Effect of Viscosity in Hypervelocity Impact Cratering," ALAA Paper 69-354, May 1969.

2 Jacocks, J L. and Kneıle, K. R , "Computation of Three-Dimensional Time-Dependent Flow Usıng the Euler Equations," Arnold Air Force Station, Tenn., AEDC-TR-80-49, July 1981

3 MacCormack, R. W. and Paullay, A J., "Computational Effelency Achieved by Tıme 
Splitting of Finite Difference Operators," AIAA Paper 72-154, January 1972.

$\$$ Eidelman, S., Colella, P. and Shreeve, R. P., "Application of the Godunov Method and Higher Order Extensions of the Godunov Method to Cascade Flow Modelling," AwA Paper 831941, ALAA 6th Computational Fluid Dynamics Conference, Danvers, Mass., July 1983.
5 Rudy. D. and Strikwerda, J., "A NonReflecting Outflow Boundary Condition For Subsonic Navier-Stokes Calculations," J. Computational Physics, Vol. 36. pp. 55-T0, 1980; Also ICASE Report No. 79-2, NASA Langley Research Center, Hampton, VA; January 1979

6 Kneile, K. R., Todd, D. C. and Jacocks, J. L., "Characteristic Boundary Conditions for ARO1," Arnold Air Force Station, Tenn., AEDC-TR-8228, May 1983.

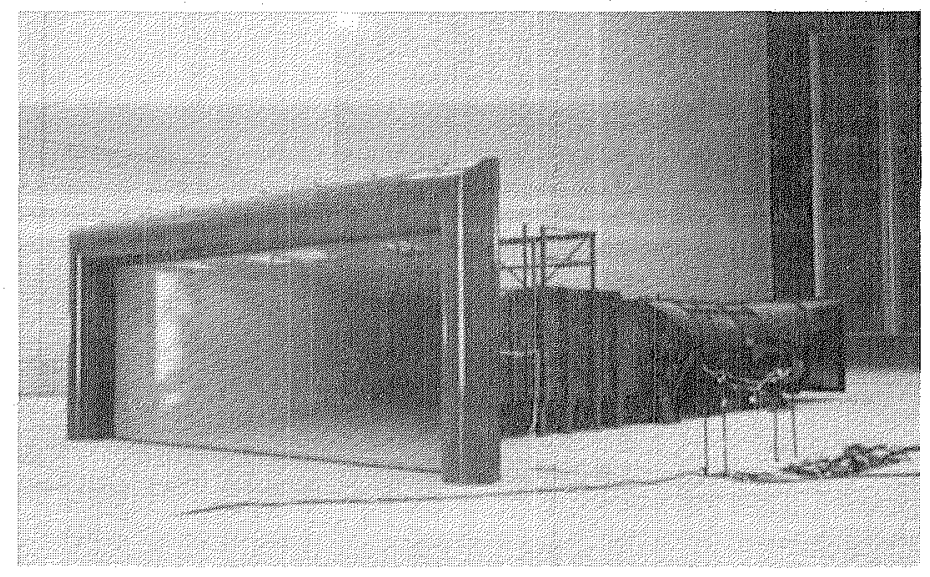

a) View showing the inlet model components: inlet cowl. nozzle, and the test section.

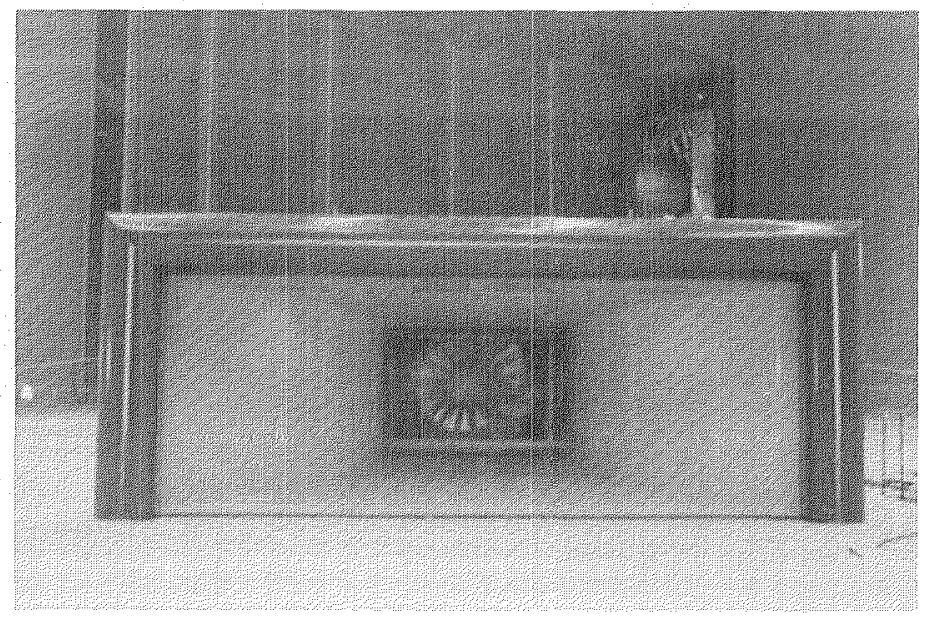

b) View looking at the front into the tunnel inlet.

Fig. 1 Different views of the inlet model. 


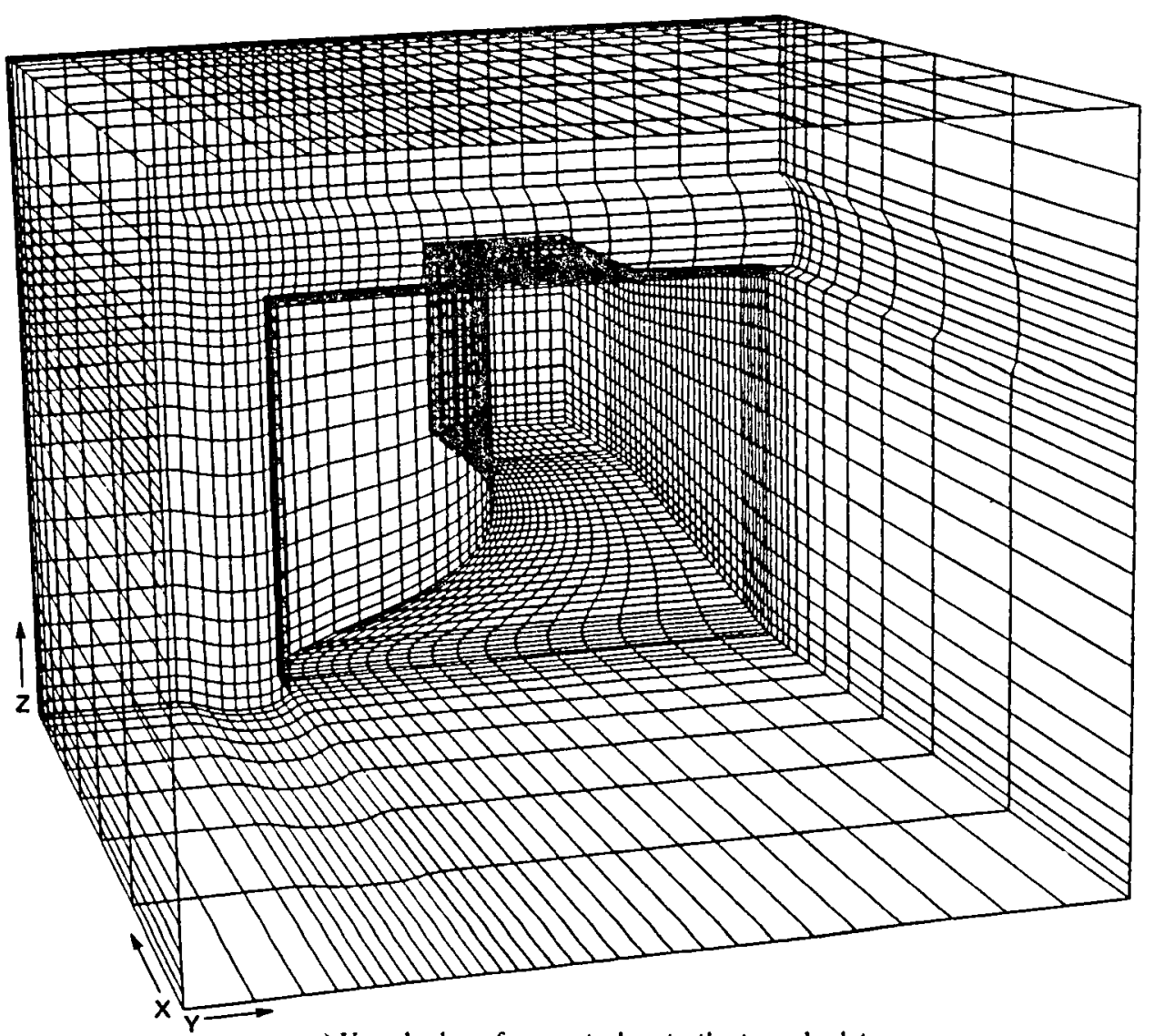

a) View looking from outside into the tunnel inlet

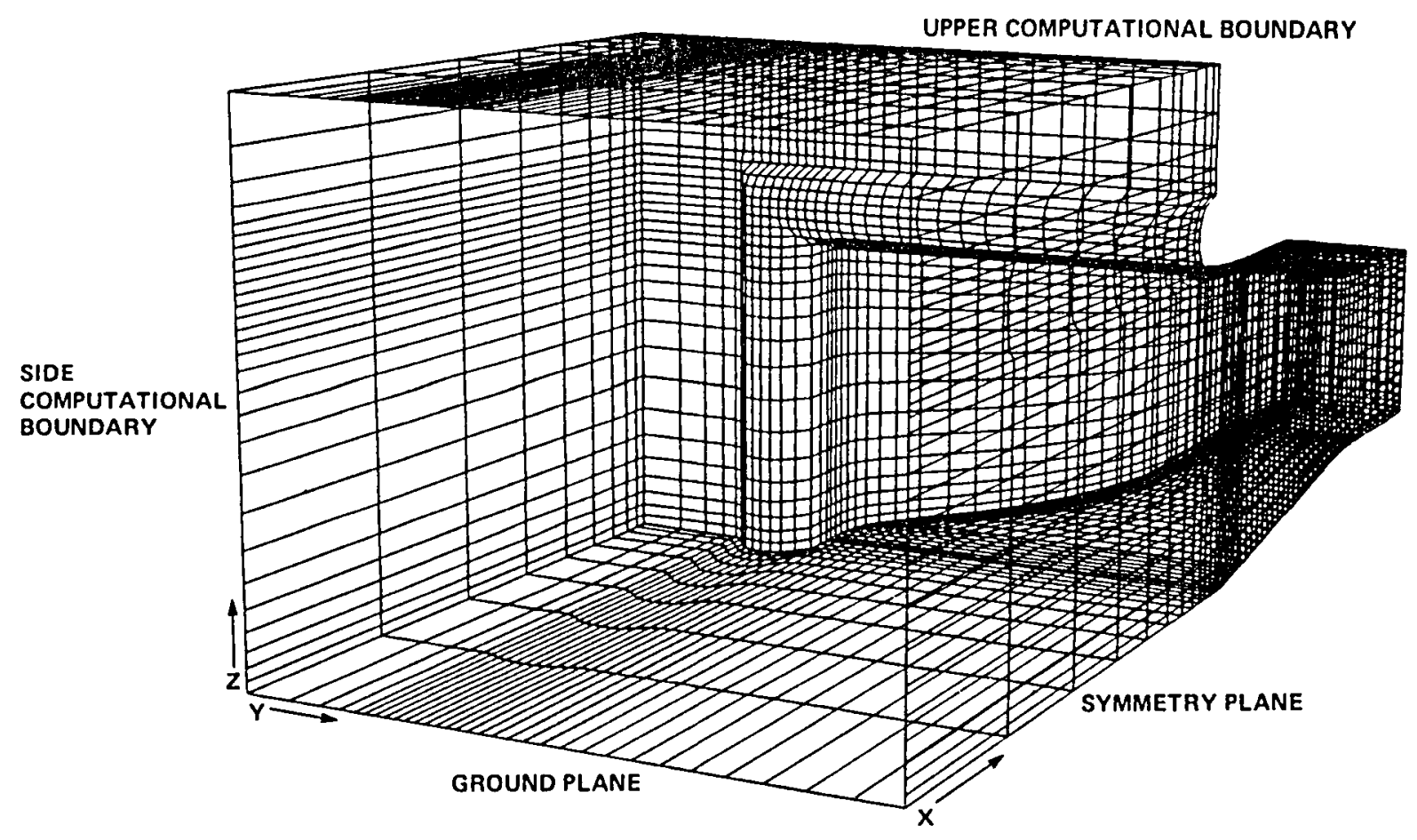

b) View lookıng at the symmetry plane and into the tunnel inlet

Fig. 2 Vanous perspective views of the inlet model of the NFAC Open Return Wind Tunnel 


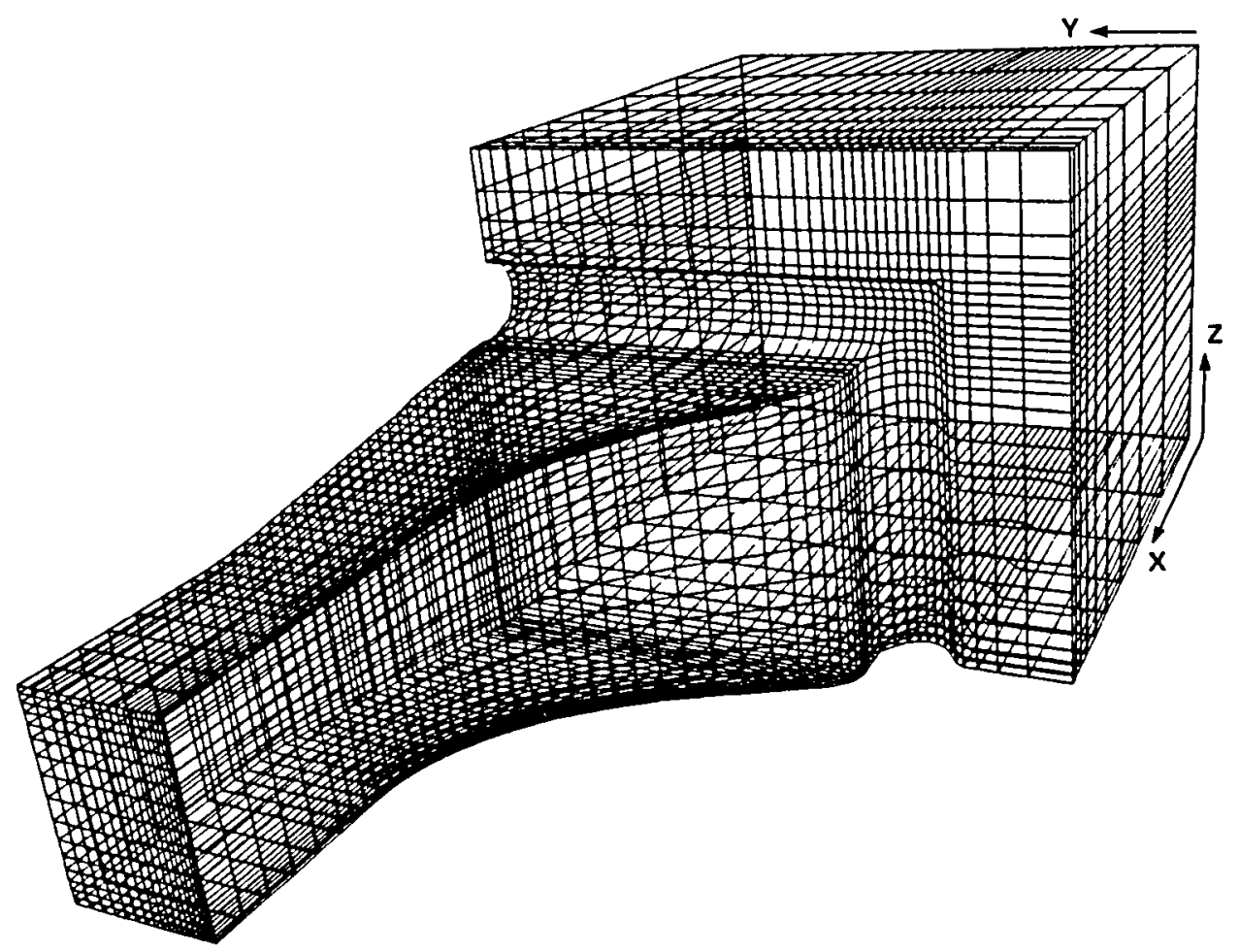

c) View looking from behind at the inlet model

Fig 2 Concluded 

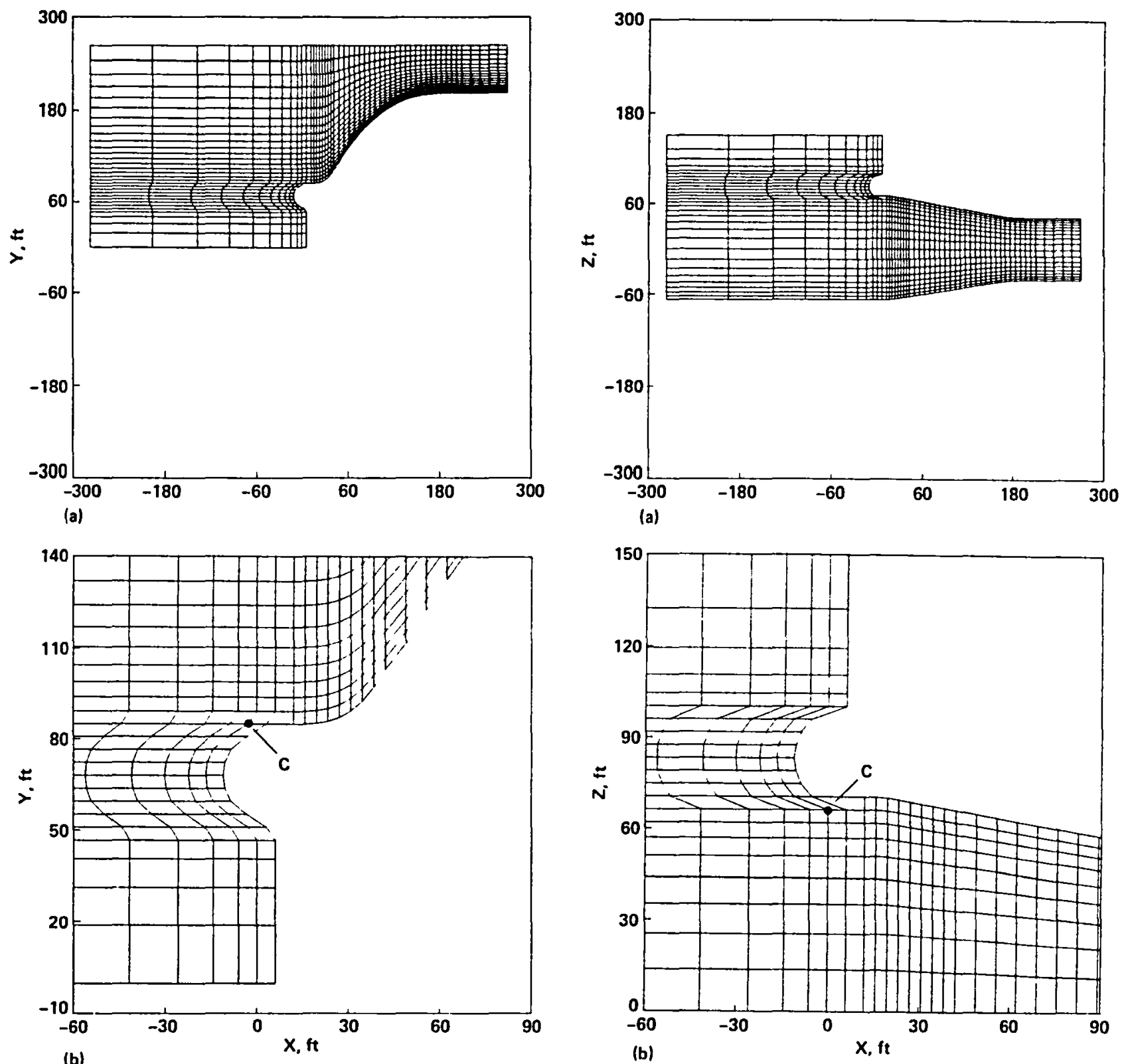

Fig 3 Planar gnd in the z-plane a) Complete z-plane gnd, b) grid enlarged near the inlet cowl

Fig 4 Planar gnd in the $y$-plane b) grid enlarged near the inlet cowl 


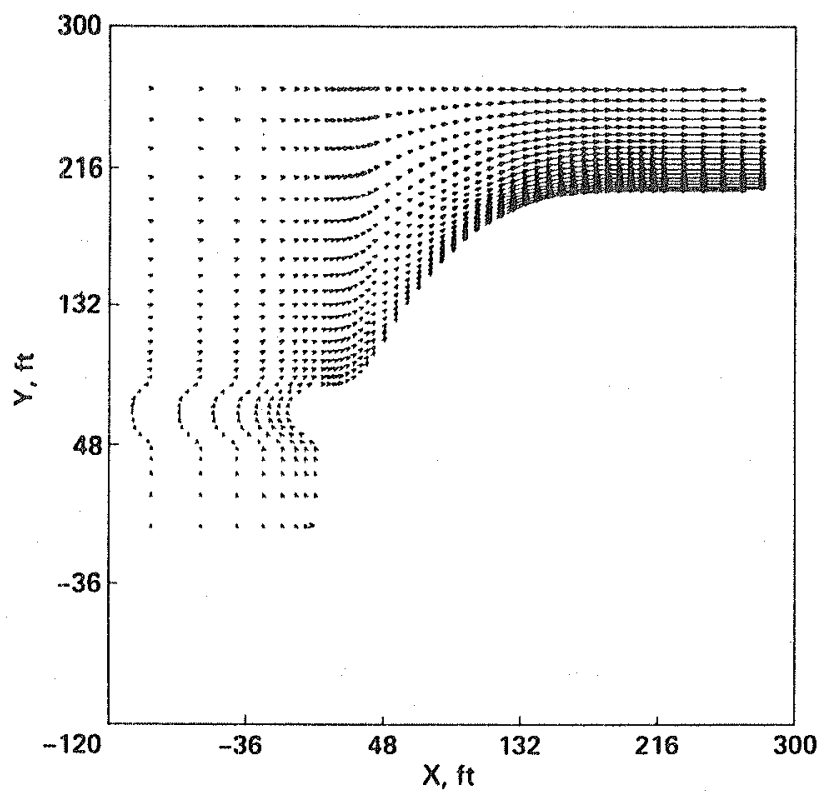

a) Vector plot showing general behavior of the flow

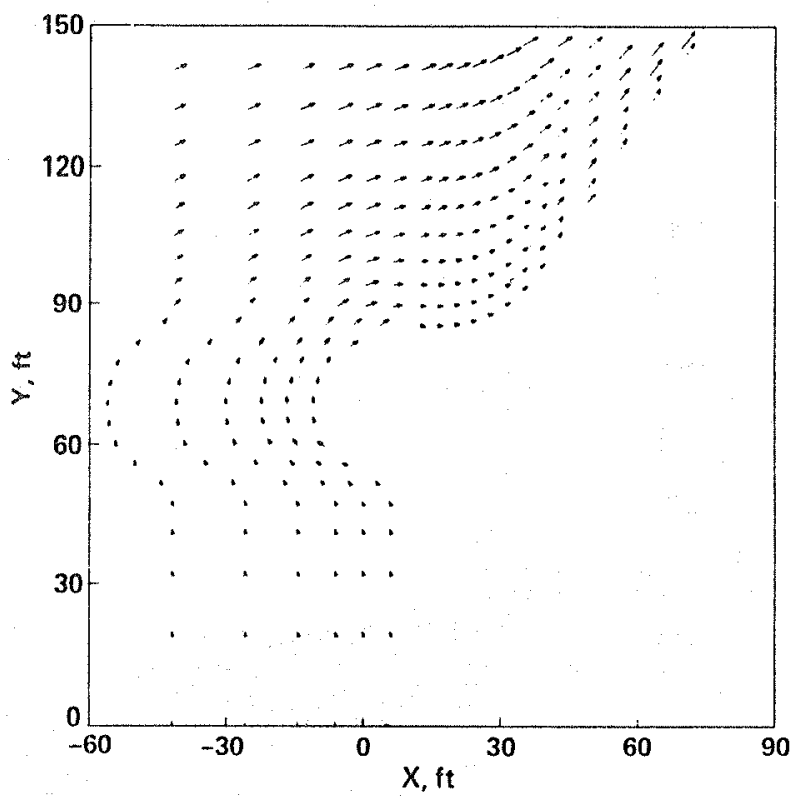

b) Enlarged view of velocity vectors near the inlet cowl.

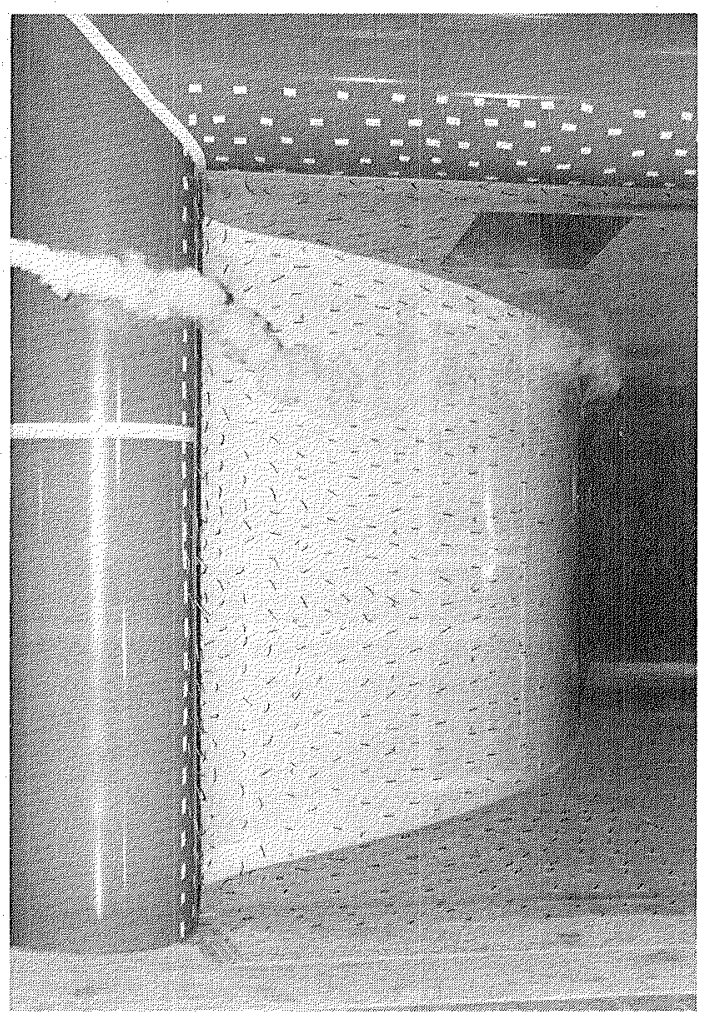

c) Smoke flow and the tufts showing the recirculation bubble immediately downstream of the cowl

Fig. 5 Velocity vectors in the z-plane. 

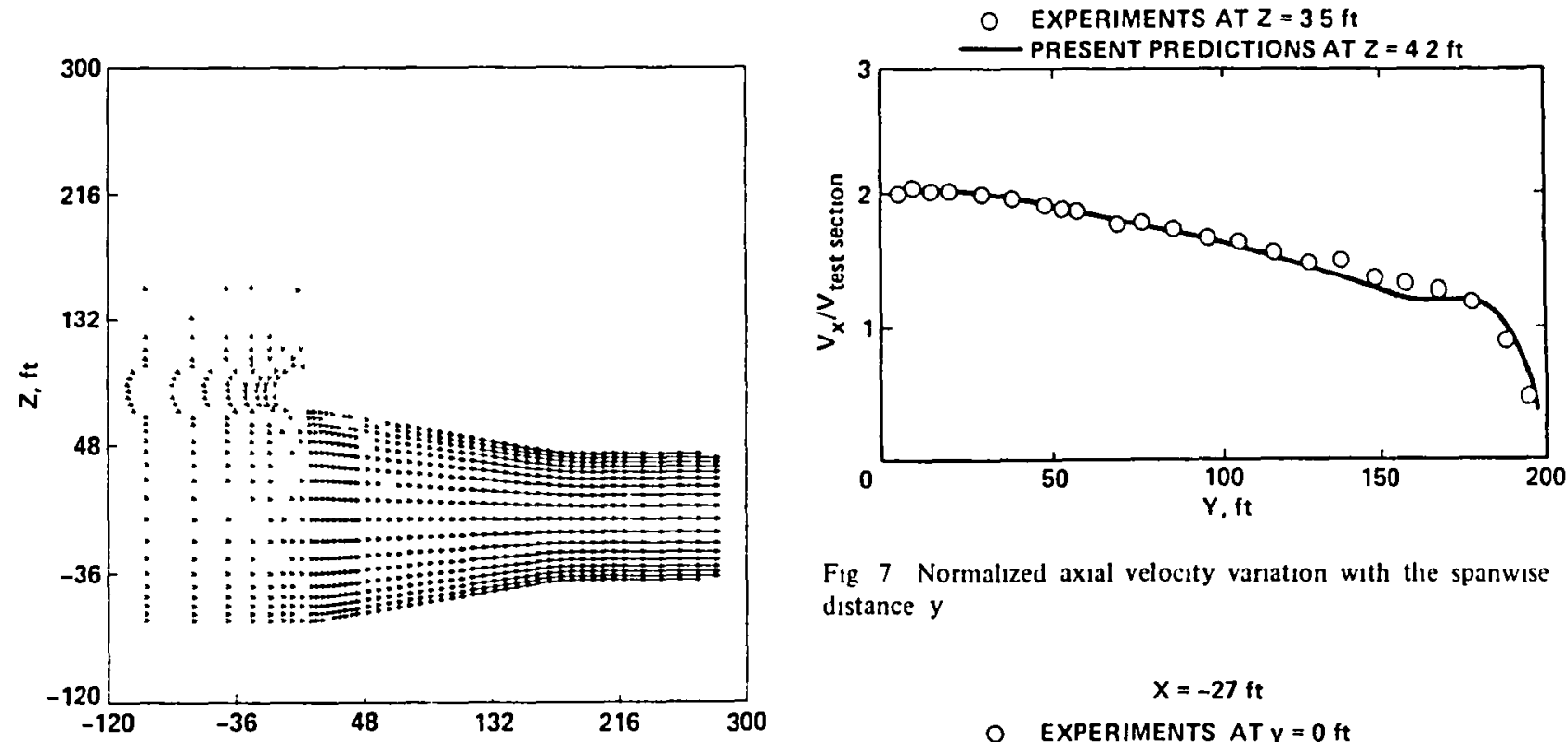

Fig 7 Normalized axial velocity variation with the spanwise distance $y$

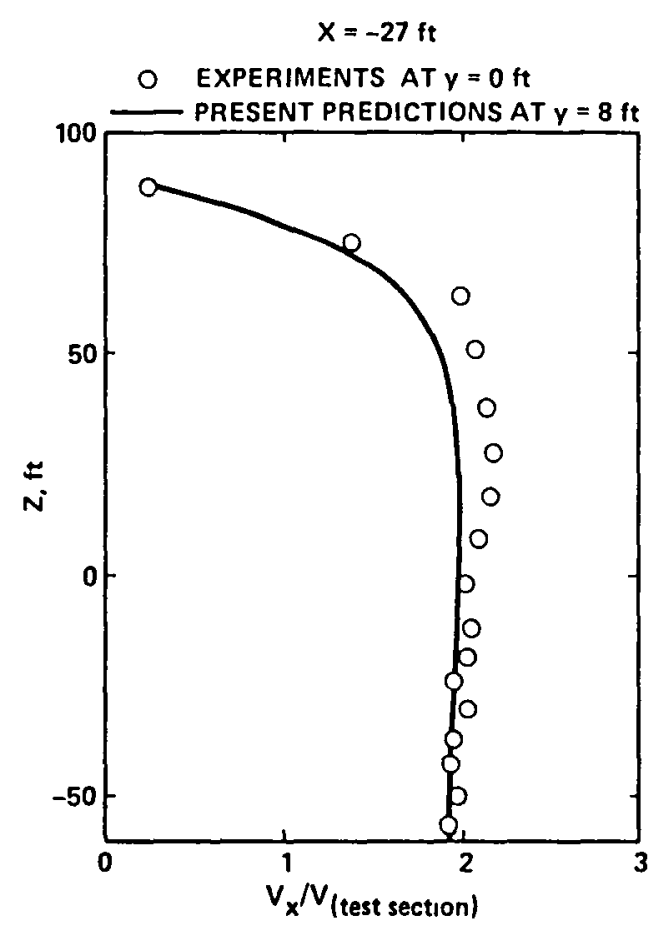

Fig 6 Velocity vectors in the $y$-plane a) Vector plot showing general behavior of the flow, b) enlarged view of the velocity

Fig 8 Normalized axial velocity variation with the height $z$ vector near the inlet cowl 


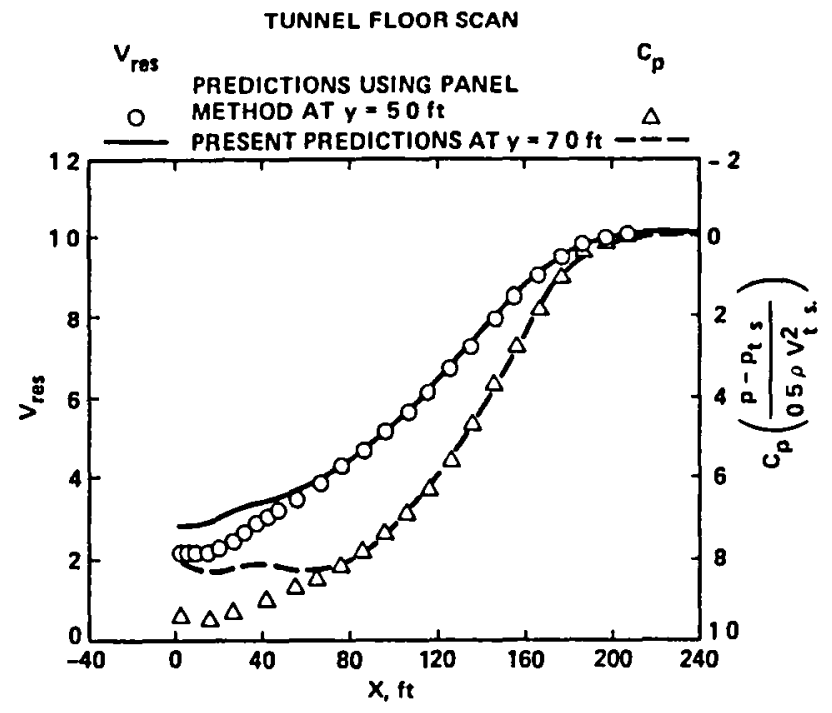

Fig 9 Tunnel floor centerline pressure and velocity (resultant) vanation with the downstream distance

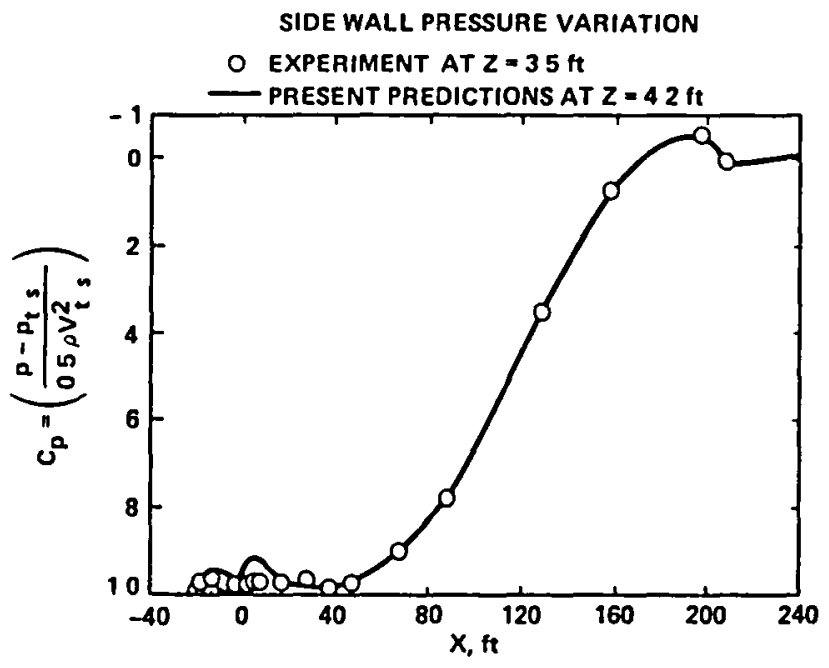

Fig 10 Pressure variation on the side wall centerline with downstream distance $x$ 

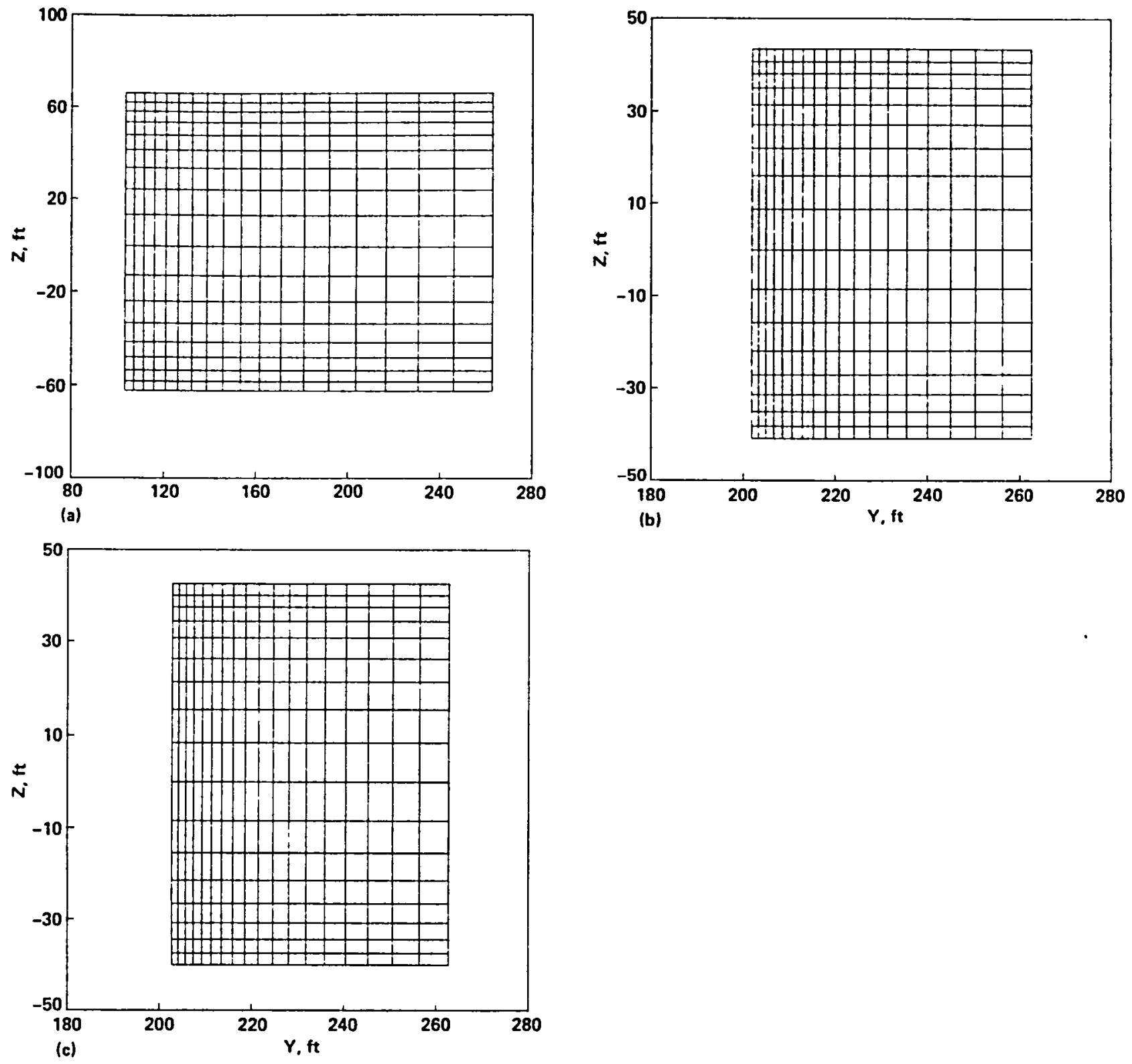

Fig 11 Crossflow plane grid a) $x=36 \mathrm{ft}, b) x=170 \mathrm{ft}, c) x=260 \mathrm{ft}$ 

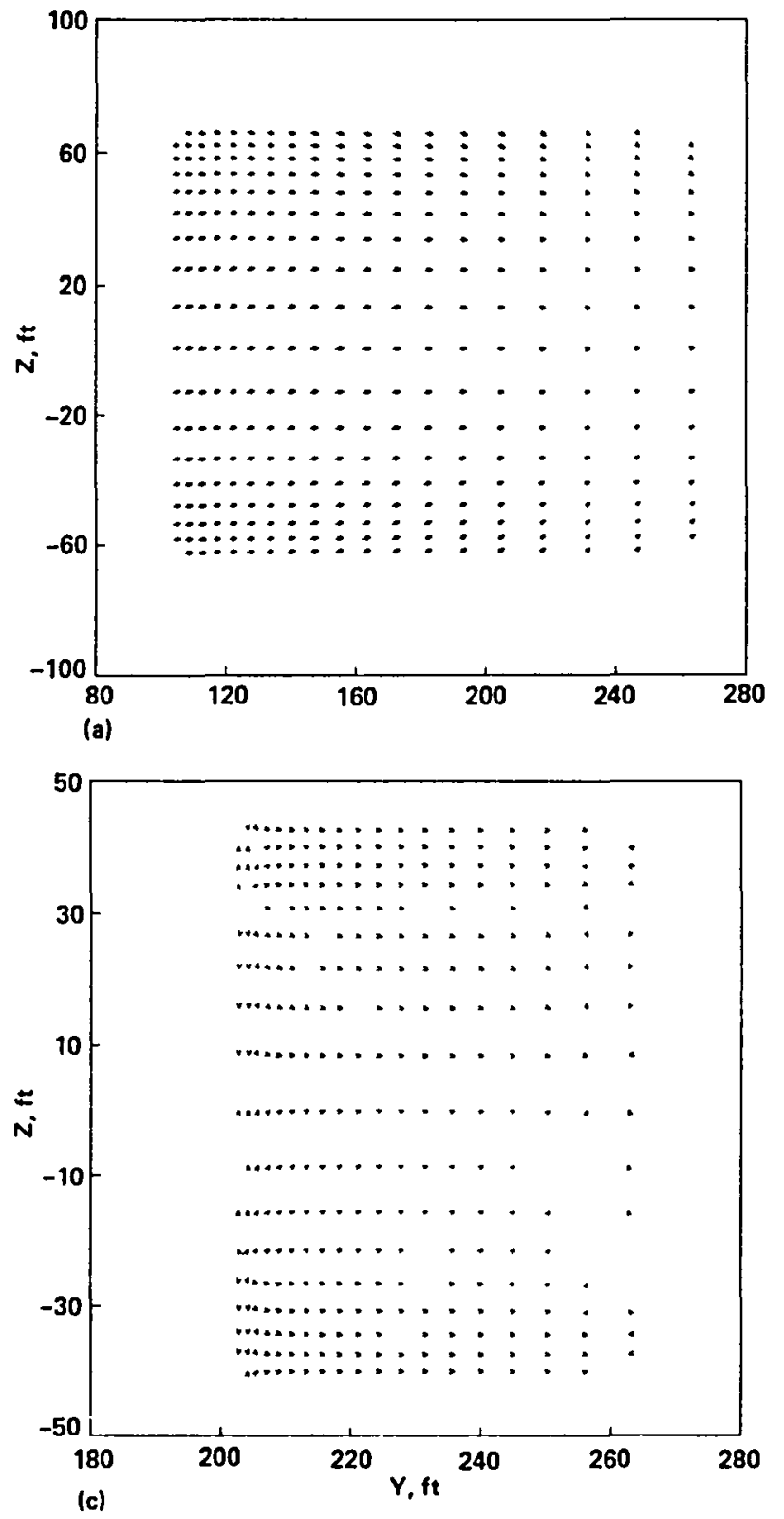

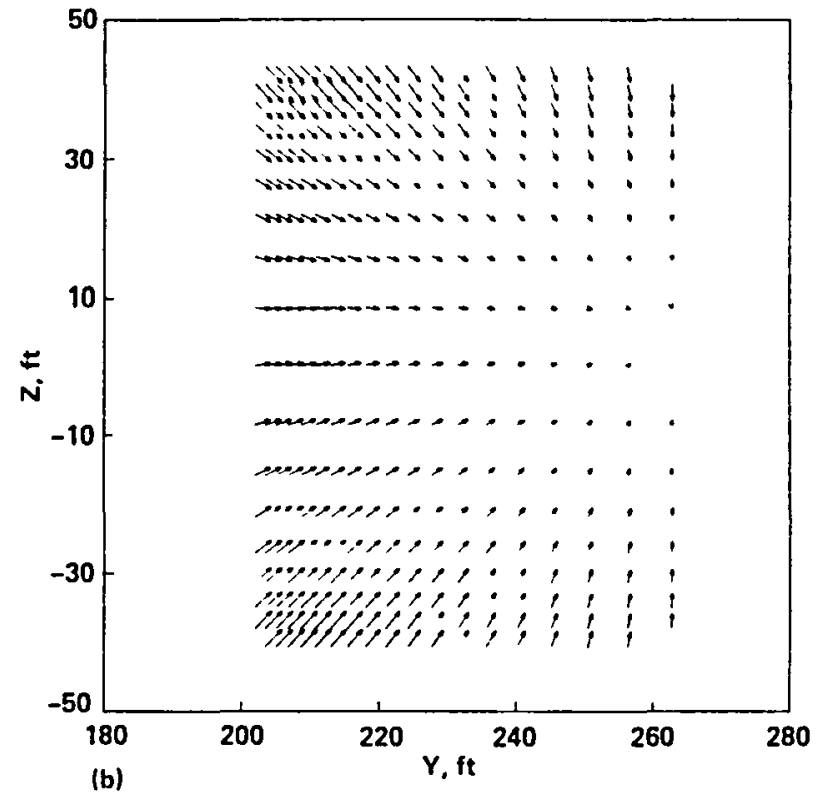

(b)

Fig 12 Crossflow velocity vectors a) $x=36 \mathrm{ft}, b) x=170 \mathrm{ft}, c) x=260 \mathrm{ft}$ 

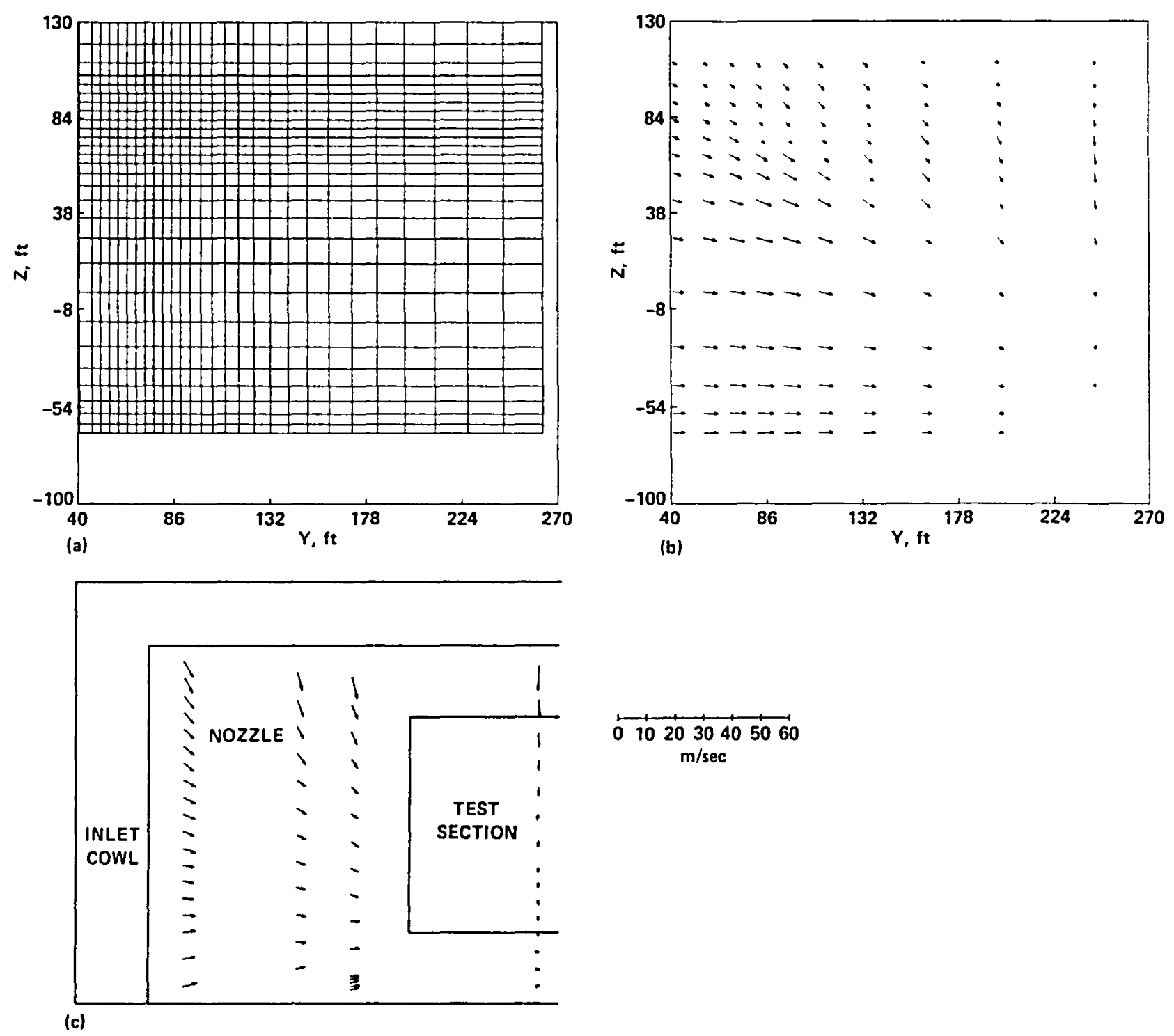

Fig 13 Companson of crossflow plane velocity vectors at $x=-27 \mathrm{ft}$ a) Crossflow plane grid, b) predicted velocity vectors, c) velocity vectors from expenment 


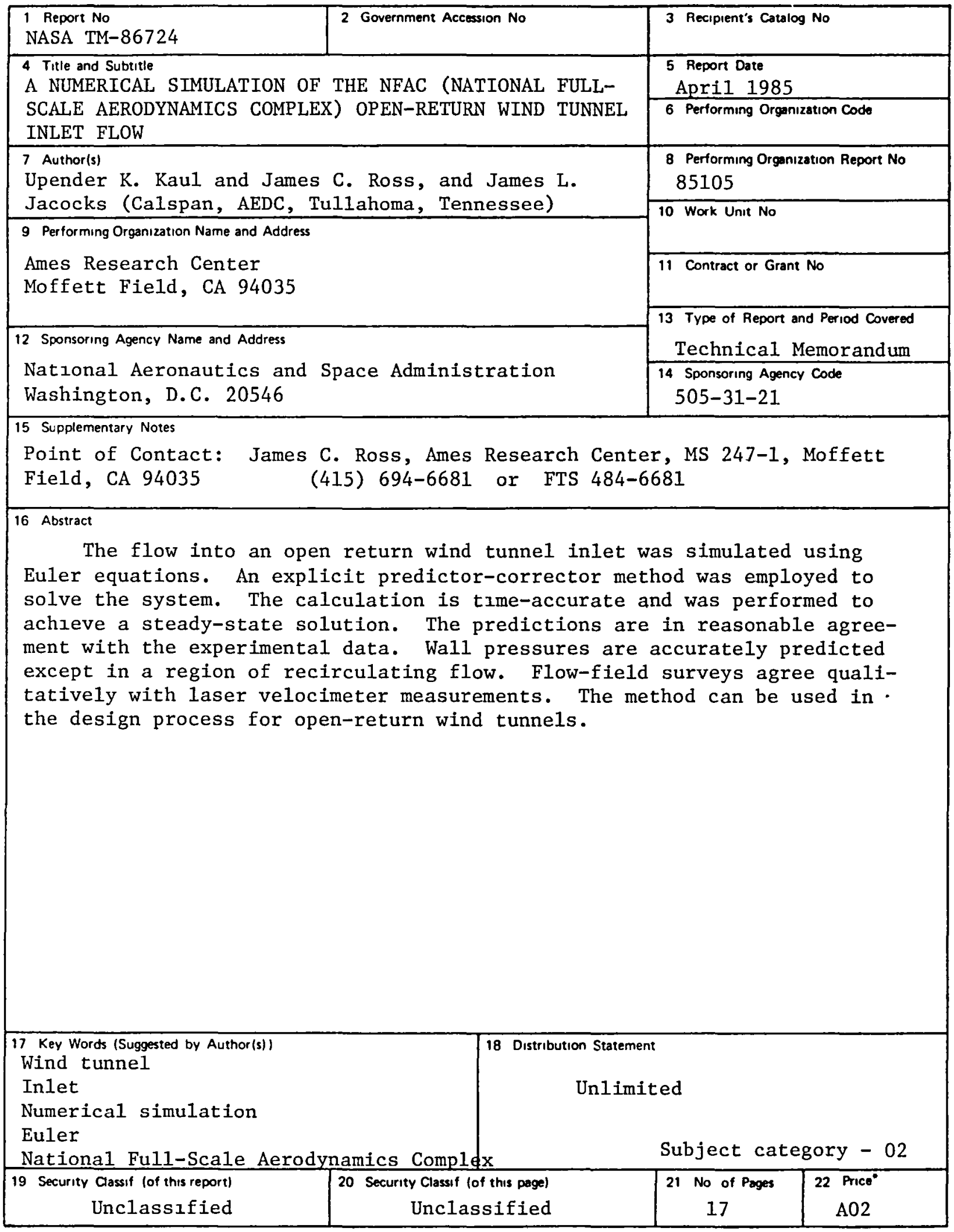

-For sale by the National Technical Information Service, Springfield, Virginia 22161 
End of Document 